\title{
AKTIVITAS BERMAIN SEBAGAI KONTEKS DALAM BELAJAR MATEMATIKA DI SEKOLAH DASAR DENGAN PENDEKATAN MATEMATIKA REALISTIK
}

\author{
Gregorius Sebo Bito \\ Universitas Flores Ende Nusa Tenggara Timur \\ e-mail: eris391@yahoo.co.id
}

\begin{abstract}
Plays is joyfull activity for Elementary School Students. This reality as something advatages for using that in mathematics learning. There are some spaces in Realistic Mathematics Education Approach for using plays as starting point to developing mathematical concept. This paper describes some examples about using play activities as context for facilitate students learning mathematics with meaning and joyfull.
\end{abstract}

\begin{abstract}
Abstrak: Bermain merupakan kegiatan yang menyenangkan bagi anak usia Sekolah Dasar. Kenyataan ini merupakan sesuatu yang menguntungkan untuk digunakan dalam pembelajaran matematika. Pendekatan Pendidikan Matematika Realistik (PMR) memberi ruang untuk menggunakan aktivitas bermain sebagai starting point pengembangan konsep matematika. Makalah ini menyajikan contoh bagaimana sebuah aktivitas bermain dapat digunakan sebagai konteks untuk memfasilitasi siswa belajar matematika secara bermakna dan menyenangkan.
\end{abstract}

Kata Kunci: aktivitas bermain, konteks, matematika realistik

\section{PENDAHULUAN}

Pada hakikatnya, matematika adalah suatu disiplin ilmu yang muncul dari sebuah proses peradaban manusia yang sangat panjang di bumi ini (Manfaat, 2010:11). Dengan kalimat lain, matematika diperoleh dari proses mematematisasi realitas (Van den Heuvel-Panhuizen, 1996:12). Dengan demikian, belajar matematika berarti belajar tentang realitas kehidupan manusia. Oleh karenanya, belajar matematika harus diawali dengan realitas yang dialami oleh orang yang akan belajar matematika.

Menurut Piaget, anak usia sekolah dasar berada pada rentangan usia dimana mereka masih berpikir konkrit. Sementara sifat matematika yang dipelajari sangat abstrak. Kesenjangan inilah yang membuat sebagian besar siswa sangat sulit untuk mempelajari matematika. Gravemeijer (1999) menyatakan bahwa kadang orang sulit memahami matematika karena adanya jurang pemisah antara kehidupan kesehari- annya dengan apa yang dikenal sebagai matematika formal.

Anak usia SD suka dengan aktivitas bermain. Kenyataan ini seharusnya dipandang sebagai sebuah keuntungan untuk dieksplorasi dalam proses pembelajaran matematika. Proses eksplorasi ini lebih bertujuan untuk menempatkan matematika sebagai bagian dari pengalaman hidup siswa. Dengan cara seperti ini, anak akan belajar matematika secara bermakna dan menyenangkan.

Belajar dikatakan bermakna jika suatu proses belajar konsep matematika yang baru dihubungkan dengan struktur pengertian yang sudah dimiliki oleh siswa yang sedang belajar (Suparno, 1997: 54).

Contoh struktur pengertian yang sudah dimiliki siswa adalah masalahmasalah realistik yang dapat dibayangkan atau yang dialami siswa. Hal ini berarti, suatu pengetahuan akan bermakna bagi siswa jika proses belajar melibatkan masalah realistik atau dilaksanakan dalam 
dan dengan suatu konteks (Wijaya, 2012: 31), salah satunya dengan konteks yang berhubungan dengan kegiatan bermain anak.

Meskipun demikian, tidak serta merta sebuah aktivitas bermain yang sering dilakukan oleh anak-anak langsung diterapkan begitu saja dalam proses pembelajaran. Guru harus memanipulasi aktivitas aktivitas bermain yang dilakukan anak setiap hari dengan tujuan memperkenalkan konsep matematika. Maksudnya adalah bahwa perlu adanya orientasi aktivitas bermain anak di awal pembelajaran sebagai bagian dari tahap awal pengembangan konsep matematika berupa masalah kontekstual yang berhubungan dengan aktivitas bermain anak.

\section{A. PENDIDIKAN MATEMATIKA REALISTIK}

Pendidikan matematika realistik muncul berdasarkan interpretasi dari pendapat Hans Freudental bahwa matematika merupakan aktivitas manusia (Gravemeijer, 1994: 82). Pendapat Hans Freudental ini berarti matematika memiliki nilai yang manusiawi sehingga sebaiknya tidak dipandang sebagai suatu produk jadi yang harus ditransfer secara langsung sebagai matematika siap pakai, melainkan harus dikonstruksi atau ditemukan sendiri oleh siswa (constructivism).

Pendapat Freudental ini sangat jelas merekomendasikan suatu pembelajaran matematika yang menekankan pada aktivitas siswa. Dalam aktivitas tersebut, siswa dibimbing secara terbatas sehingga secara bertahap diharapkan seolah-olah siswalah yang menemukan kembali (reinvention) konsep matematika. Proses ini diharapkan siswa dapat mengalami bagaimana sebuah pengetahuan matematika ditemukan. Ini berarti, siswa difasilitasi (giuded) untuk merasakan tahap demi tahap proses penemuan sebuah pengetahuan matematika oleh ahli yang menemukannya.

Treffers (1987) seperti yang dikutip oleh Wijaya (2012: 21-23) merumuskan lima karakteristik dalam PMR yaitu: penggunaan konteks, penggunaan model untuk proses matematisasi progresif, pemanfaatan hasil konstruksi siswa, interaktivitas dan keterkaitan. Dengan demikian, pendekatan PMR memberikan ruang bagi penggunaan konteks sebagai langkah awal untuk mengembangkan konsep matematika.

Salah satu fungsi dari konteks adalah memberikan siswa suatu akses yang alami dan motivatif menunju konsep matematika (Wijaya, 2012: 33). Hal ini berarti, konteks akan dikembangkan menjadi konsep matematika melalui sebuah proses matematisasi. Matematisasi adalah sebuah proses mematikakan sebuah konteks, yaitu proses menerjemahkan sebuah konteks menjadi konsep matematika (Wijaya, 2012: 33).

Ini berarti, pemilihan konteks harus relevan dengan konsep matematika yang akan dipelajari karena konteks yang dipilih memuat konsep matematika dalam bentuk yang mudah dimengerti (dibayangkan) dan dikenal oleh siswa. Sebagai contoh, dalam konteks transportasi terdapat fenomena naik dan turun penumpang. Fenomena ini dikenal dan atau dapat dibayangkan siswa sehingga dapat digunakan pada tahap awal pembelajaran penjumlahan dan pengurangan bilangan cacah.

\section{B. BERMAIN SEBAGAI KONTEKS BELAJAR MATEMATIKA DENGAN PENDEKATAN PMR.}

Anak-anak sangat suka bermain sebelum dan saat mereka mulai memasuki sekolah formal. Aktivitas bermain yang paling dominan terjadi ketika anak berada di rumah misalnya bermain game, menyusun puzzle, berolahraga dan sebagainya.

Dengan demikian, ketika anak ke sekolah, mereka telah memiliki pengalaman pengalaman yang tidak mereka sadari sebagai pengalaman informal matematika.

Griffiths (Haylock \& Tangata, 2007: 139) menyatakan bahwa penggunaan aktivi- tas bermain dalam pembelajaran matemati- ka dapat membantu anak untuk memandang matematika sebagai pelajaran 
yang menyenangkan, bersifat sosial dan banyak berguna dalam kehidupan.

Penggunaan beragam permainan di awal pembelajaran matematika akan membuat siswa senang untuk belajar matematika. Selain itu, dalam kegiatan bermain, akan terjadi interaksi sosial antara siswa. Dari interaksi ini diharapkan dapat ditemukannya suatu konsep matematika.

Pendidikan Matematika Realistik sangat menekankan pentingnya interaksi sosial dalam pembelajaran (Wijaya, 2012: 72). Proses interaksi ini diharapkan terjadi sejak awal pengembangan konsep matematika. Jika dalam belajar terjadi proses komunikasi berbagai gagasan antar siswa, maka belajar akan menjadi lebih efektif dan efisien.

Agar aktivitas bermain dapat bermanfaat seperti yang disebutkan di atas, maka pemilihan jenis kegiatan bermain dalam pembelajaran matematika harus memenuhi syarat: (1) memiliki tujuan untuk pengembangan konsep matematika dan aktivitas tersebut menyenangkan bagi anak; (2) aktivitas bermain harus dengan konteks yang bermakna; (3) menuntut tanggung jawab siswa dan dapat diawasi; (4) dapat diulang, dipraktikan dan dikuasai oleh siswa.

Tucker (2005: 6) berpendapat bahwa untuk mendukung pengembangan konsep matematika menggunakan aktivitas bermain dibutuhkan kualitas keterlibatan guru pada beberapa tingkatan. Keterlibatan guru dimulai dari perencanaan, menyediakan sumber daya yang diperlukan untuk menstimulasi peluang pembelajaran, atau melibatkan diri secara langsung dalam permainan (Haylock \& Tangata, 2007: 139). Selama kegiatan bermain berlangsung, guru dapat memperkenalkan kosa kata matematika serta menggiatkan dialog dan penalaran matematika (Haylock \& Tangata, 2007: 139). Lewis seperti yang dikutip Pound (Haylock \& Tangata, 2007: 139) meyatakan bahwa kualitas kegiatan bermain dapat memfasilitasi siswa berpeluang untuk membuat keputusan, membayangkan, menalar, memprediksi, merencanakan, mengujicoba berbagai strategi dan mencatat.

Dalam PMR, kegiatan bermain dapat dijadikan konteks pada tahap awal pengembangan konsep matematika. Posisi kegiatan bermain dapat dijadikan sebagai aktivitas paling awal (aktivitas situasional) dalam belajar matematika. Dari konteks ini, siswa akan melakukan matematika (menggunakan model) secara bertahap mulai dari model situasi (konkrit) sampai pada tahap ditemukannya suatu pengetahuan matematika (model formal).

Gravemeijer (1994: 101) menyebutkan, pada awalnya siswa mengembangkan model atau cara yang sesuai dengan pemahamannya. Model ini masih bersifat kontekstual dan khusus dari (model of) situasi masalah yang diberikan. Model inilah yang menjadi dasar untuk mengembangkan pengetahuan matematika formal. Setelah proses generalisasi dan formalisasi model tersebut secara bertahap diarahkan untuk menuju model untuk (model for) pemikiran matematika pada tingkat yang formal seperti yang tertera pada Gambar.1 berikut.

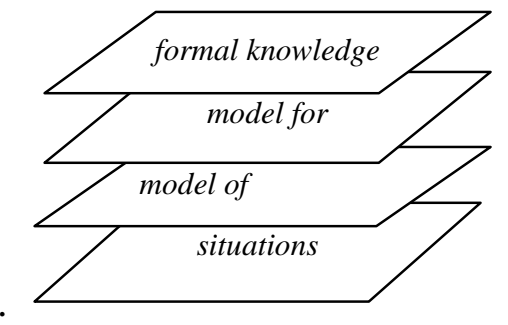

Gambar.1

Pengembangan model dalam PMR

Namun, yang perlu diketahui adalah bahwa siswa tidak menyadari bahwa kegiatan bermain yang sering mereka lakukan berhubungan dengan apa yang akan mereka pelajari. Oleh karena itu, butuh suatu aktivitas dimana guru menghubungkan pengalaman siswa secara matematis di kelas yang oleh Frans Morerlands dinamakan tahap orientasi lingkungan secara matematis.

Frans Moerlands (Sugiman, 2011: 8) mendiskripsikan tipe pendekatan realistik dalam gagasan gunung es (iceberg) yang 
mengapung di tengah laut. Proses pembentukan gunung es di laut selalu dimulai dari bagian dasar di bawah permukaan laut dan seterusnya akhirnya terbentuk puncak gunung es (Gambar. 2) yang muncul di atas permukaan laut.

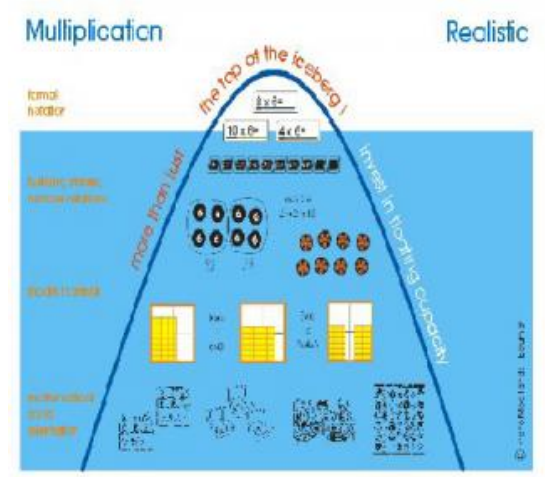

Gambar 2.

Contoh Iceberg untuk pembelajaran perkalian

Bagian dasar gunung es lebih luas dari pada puncaknya, dengan demikian konstruksi gunung es tersebut menjadi kokoh dan stabil.

Dalam hubungannya dengan pembentukan konsep matematika, matematika formal hanyalah tujuan yang paling akhir. Untuk mencapai tujuan tersebut, dibutuhkan serangkaian usaha yang merupakan fondasi agar konsep matematika yang dipelajari benar-benar dipahami dan bermakna siswa.

Dalam model gunung es Moerlands, terdapat empat tingkatan aktivitas, yakni: (1) orientasi lingkungan secara matematis, (2) model alat peraga, (3) pembuatan pondasi (building stone), dan (4) matematika formal.

Untuk menghubungkan kegiatan bermain dengan konsep yang akan dipelajari, orientasi kegiatan bermain secara matematis sangat penting. Pada tahap ini anak akan dibiasakan menyelesaikan masalah seharihari tanpa harus mengaitkan secara tergesagesa pada matematika formal. Anak akan memodelkan secara situasi permasalahan matematika yang berhubungan dengan konteks yang diberikan. Kegitan matematis yang bersentuhan dengan berbagai konteks real yang menuju pada suatu konsep matematika akan menjadi landasan bagi siswa dalam tingkatan selanjutnya.

\section{IMPLEMENTASI}

Terdapat banyak kegiatan bermain dapat dieksplorasi menjadi aktivitas situasional pada tahap awal pengembangan model dalam Pendekatan PMR. Kegiatan yang dimaksud antara lain bermain peran, permainan yang diinisiasi oleh guru, bermain bebas dan bermain di luar ruangan. Guru perlu memilih permainan yang memiliki fenomena matematis dan mengorientasikan aktivitas bermain yang siswa kenal secara matematis.

Sebagai contoh, siswa sering bermain mobil-mobilan dan pernah memiliki pengalaman ketika menumpang angkutan umum. Dalam permainan mobil-mobilan terdapat fenomena naik-turun penumpang. Fenomena ini dapat dieksplorasi pada tahap awal pengembangan konsep penjumlahan dan pengurangan bilangan cacah dimana konteks yang digunakan adalah konteks Transportasi.

Karena siswa memahami fenomena naik-turun penumpang dalam konteks transportasi tersebut, guru perlu mengorientasi siswa dalam kelas dimana siswa malakukan drama matematika dengan sebuah skenario yang telah disiapkan.

Berikut ini merupakan contoh skenario yang merupakan bagian penelitian yang dilakukan oleh Kairuddin \& Darmowijoyo (2010:71).

An angkot has 3 passengers, stop at roadside and get on 3 passengers, after derived then stop at next roadside and get off 2 passengers and get on 4 passengers. Angkot driver want to determine how many passengers in angkot at last stop.

Skenario di atas dapat dijalankan oleh siswa melalui drama menaikan dan menurunkan penumpang angkot dimana angkot 
disediakan berupa pengaturan kursi yang menyerupai angkot sebagai berikut (Gambar 3).

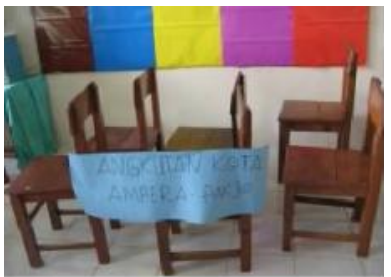

(a)

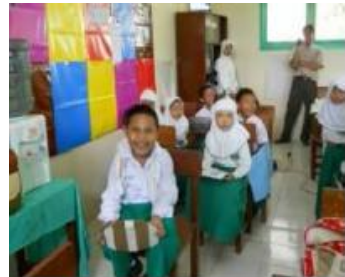

(b)
Gambar 3: (a) Kursi Angkot, (b) Sopir Angkot dan Penumpang ( Sumber: Kairuddin \& Darmawijoyo. (2010). IndoMS. J.M.E Vol.1 No. 1, pp. 67-78)

Penelitian lainnya pernah dilakukan oleh penulis (Sebo Bito \& Sugiman, 2013: 173-183) dimana Konteks fair sharing yaitu kegiatan membagi makanan ringan digunakan untuk pembelajaran operasi penjumlahan dan pengurangan pecahan.

Pembelajaran penjumlahan dan pengurangan pecahan diawali dengan role playing (Gambar 4) dimana siswa berperan sesuai skenario sebagai berikut.

Pada suatu siang sepulangnya dari pasar Bajawa, ibu membawa oleh-oleh berupa 1 renteng makanan ringan untuk Owyn. Siang itu Owyn langsung makan $1 / 5$ bagian dan pada sore harinya ia menghabiskan lagi 2/5 bagian. Sisanya akan diberikan pada temannya.

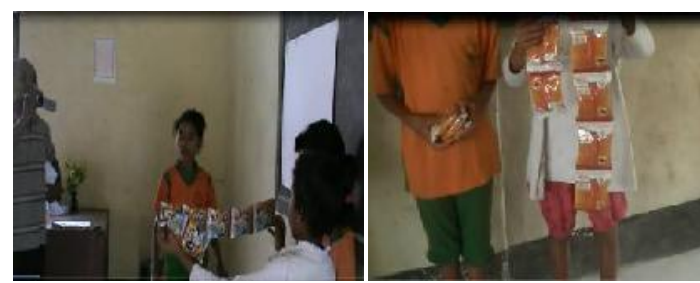

Gambar 4 :Drama membagi makanan ringan. (a).Tiga orang siswa dari Kelompok Mawar melakukan peragaan Skenario1, (b) Rufina memegang 2 bungkus makanan ringan yang diberikan Owyn pada temannya (Kiri). Telin memegang 2 bungkus makanan ringan yang dimakan siang hari dan 4 bungkus yang dimakan pada sore hari (Kanan)

(Sumber: Sebo Bito, G. \& Sugiman (2013). Eksplorasi Pembelajaran Operasi Pecahan Siswa Sekolah Dasar Kelas IV di Kabupaten Ngada NTT menurut Teori Gravemeijer. Jurnal Prima Edukasia, Vol 1-No.2, 2013.pp.173-183
Selain kedua contoh di atas, masih banyak kegiatan bermain yang dikenal siswa dapat dieksplorasi dalam pembelajaran matematika. Selain bermain peran dengan skenario yang telah dibuat guru, bermain di luar ruangan juga dapat menjadi pilihan.

Di Indonesia ditemukan banyak permainan yang memuat konsep-konsep matematematika sehingga permainan-permainan tersebut dimanfaatkan untuk pembelajaran matematika di luar ruangan kelas. Siswa telah banyak mengenal permainan tradisional yang dimainkan di tempat terbuka. Permainan tradisional ini dapat digunakan untuk tahap orientasi atau starting point pembelajaran matematika.

Sebagai contoh, beberapa permainan tradisional misalnya bermain klereng dan Patil Lele atau Benthik dapat digunakan untuk pembelajaran matematika berbasis permainan (Wijaya, 2009:6).

Benthik adalah suatu permainan tradisional yang dimainkan secara berkelompok. Setiap kelompok akan bergantian untuk memukul tongkat pendek dengan pemukul dan kemudian jarak jatuh tongkat diukur. Pemenang adalah kelompok yang memperoleh akumulasi jarak lebih besar. Proses pengukuran jarak tongkat memuat konsep pengukuran, seperti iterasi unit (Wijaya, 2009:6).

Proses pengukuran secara informal akan membawa siswa pada interaksi yang mengakibatkan adanya konflik kognitif sehingga pada akhirnya siswa dapat menggunakan pengukuran secara formal.

\section{KESIMPULAN}

Permainan anak dapat digunakan sebagai tahap orientasi dalam pembelajaran matematika. Pemilihan permainan anak harus didasari pada syarat-syarat yang telah disebutkan sebelumnya. Dalam konteks Pendekatan Matematika Realistik, syarat penting bagi pemilihan permainan terletak pada fenomena didaktik yang cocok 
dengan konsep matematika yang akan dipelajari.

\section{DAFTAR PUSTAKA}

Gravemeijer, K. (1994). Developing Realistic Mathematics Education. Utrecht: Freudenthal Institute, Netherlands.

Haylock, D., Thangata, F. (2007). Key Concepts in Teaching Primary Mathematics. London: Sage Publication

Kairuddin \& Darmawijoyo. (2010). The Indonesian's Road Transportations as the Contexts to Support Primary School Students Learning Number Operation. IndoMS. J.M.E Vol.1 No. 1, pp. 67-78

Manfaat, B. (2010). Membumikan Matematika: Dari Kampus ke Kampung. Cirebon: Eduvision Publishing.

Sebo Bito, G. \& Sugiman (2013). Eksplorasi Pembelajaran Operasi Pecahan Siswa Sekolah Dasar Kelas IV di Kabupaten Ngada NTT menurut Teori Gravemeijer. Jurnal Prima Edukasia, Vol 1-No.2, 2013.pp.173-183

Sugiman. (2011). Peningkatan Pembelajaran Matematika dengan Menggunakan Pendekatan Matematika Realistik. Tersedia di http://staff.uny.ac.id/sites/default/files /tmp/2011_PPM_Iceberg_0.pdf diakses 17/12/2012.

Suparno, P. (1997). Filsafat Konstruktivisme dalam Pendidikan. Yogyakarta: Kanisius

Tucker, K. (2005). Mathematics Through Play in the Early Years: Activities and Idea. London: Paul Chapman Publishing.

Van den Heuvel-Panhuizen, M. (1996). Assessment and Realistic Mathemamatics Education. Utrecht: CD- $\beta$ Press, Center for Science and Mathematics Education.

Wijaya, A.(2012). Pendidikan Matematika Realistik: Suatu alternatif pendekatan pembelajaran Matematika. Yogyakarta: Graha Ilmu

Wijaya, A. (2009). Manfaat Permainan Tradisional untuk PMRI: Suatu Kajian. Dipresentasikan pada Seminar dan Workshop PMRI di Universitas Sanata Dharma. Yogyakarta, 28 April 2009. Tersedia di http://staff.uny.ac.id. diakses $17 / 12 / 2012$ 